\title{
Mobile communities: How viable are their business models? An exemplary investigation of the leisure industry
}

\author{
Petra Schubert · J. Felix Hampe
}

(C) Springer Science + Business Media, LLC 2006

\begin{abstract}
Communities (especially Virtual Communities) of Interest have been the focus of substantial discussion in academic literature. This paper addresses Communities of Interest within the leisure industry and discusses possible business models for the parties operating the platform. The described community platform is an innovative value added service concept for a mobile coordination support for individuals-A Mobile Community Support System. In this paper we extend the discussion about mobile communities to hybrid communities. The communities are hybrid in two ways: they use two different access channels, the Web and mobile devices, and they are built on real-world leisure communities that constitute themselves in the form of buddy lists in the virtual world of an ICT supported platform. We briefly depict the state of the art of IT in the leisure industry and describe the empirical aspects of the project objectives of the MCOR (Mobile Community Online Reservation) system. We conclude with some final remarks about design considerations and a blueprint for future research.
\end{abstract}

Keywords Mobile communities $\cdot$ Mobile CRM $\cdot$ Mobile commerce $\cdot$ Mobile business . Leisure industry

By the end of 2002 over a billion people around the world own mobile phones ([12], for constantly updated statistics of the Mobile Telephony Market and GSM in particular see [18]). Daily life and work in metropolitan areas already reflect the ubiquitous availability of mobile communication. Everywhere, millions of mobile users are chatting, messaging, accessing data, and entertaining themselves. Since people do not like to carry multiple devices and personal conversation is still the most important way of communication, it is very likely

P. Schubert

University of Applied Sciences Basel (FHBB), Institute for Business Economics (IAB), Switzerland e-mail: petra.schubert@fhbb.ch

\section{J. F. Hampe}

School of Computing and Information Science University of South Australia, City West Campus, North Terrace, Adelaide SA 5000, Australia

e-mail: felix.hampe@unisa.edu.au 
that the use of mobile phones will be the most accepted mobile device for future city dwellers. Our research tries to tap this potential by proposing a mobile service for distributed physical communities which try to coordinate their leisure time activities while moving around.

As network speed increases and mobile devices become capable of more sophisticated services (such as the here described J2ME technology), there is general agreement that the missing ingredient in mobile commerce mass adoption are applications that create a unique mobility value proposition for the customer. Exactly this point was seen in the early studies on Mobile Commerce [14, 67] but very few value added services (VAS) have been successfully launched since then. Our applied design research aims to contribute by trying to tie the concept of physical communities to mobile applications. We are aiming to leverage the value of both the "network of friends" and the "use of mobile devices." In the categorization scheme proposed by [12] our service would be assigned to the category of "Interactive Services".

In order to motivate our approach and underpin the general considerations with an example, we assume the following scenario. In most societies we observe a paradox: a constantly growing group of employees is increasingly interested in leisure time activity, but a significant proportion of them is regularly working overtime. In many cases they are young, sportive and wellness-oriented and belong to a high income class. Most often these people are severely time constrained and are usually unable to plan their leisure activities long-term in advance. An example of such a situation is as follows: To discover by 5:30 p.m. that they will be able to leave the office at 6:30 p.m. that day. Subsequently in order to organise their evening activities at short notice they need to know the availability of fellow sports friends and book any necessary resource (racket-court, trainer etc.) for 7:00 p.m. Thereafter, they might want to meet friends for a drink or snack at a reserved table. Today, these appointments can only be realised by calling each party involved personally. This is where a mobile community online reservation (MCOR) system comes in: by supporting the reservation processes as well as the management of appointments by a mobile support system, this group of people would succeed in arranging their leisure time activities at short notice. All reservations and the notification of each person about the requested event or invitation will be immediately sent out by the support system and any incoming response is issued automatically choosing the appropriate channel based on a preference profile. The underlying mobile community approach deserves some reflection on the existing literature on communities.

This paper attempts to make two contributions to the literature. The first is a general framework for designing business models for mobile services. The framework synthesizes previous work on virtual communities, mobile commerce, and business models and extends that work into the area of mobile services. The paper explores the community actors, their role, as well as different kinds of relationships among the players (information flow, activity triggers, and financial flows). It takes up the current question on valid revenue models for mobile services (discussed in detail by [63]) applying it to the application context of a mobile community. The second contribution is the presentation of a concrete application of a mobile service that we used for the study of the effective launch of such a service. Discussions and interviews with the software developers and the future operators of the platform gave us the unique opportunity to discuss our findings with the parties involved in the development process. They provided us with direct feedback on the design of the application as well as the envisioned business model. The access to this first-hand information enabled us to go beyond a mere speculation about the eventual success of such a platform.

The research methodology used is an explorative analysis of a real-world business application. We used the inductive approach suggested by [7] which is common in marketing literature. The article reflects design research [70] and makes use of the selected case description of a wellness centre.

$\underline{\text { Springer }}$ 


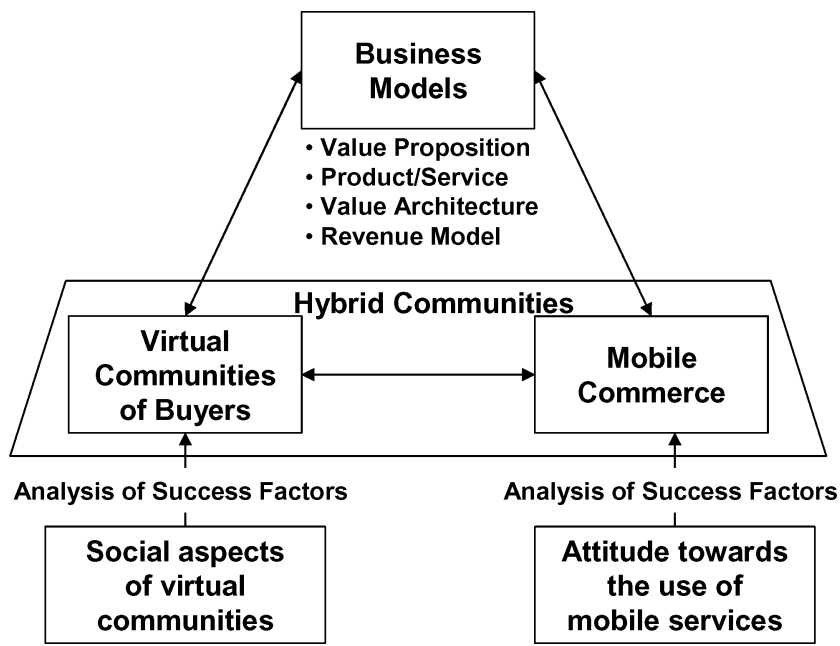

Fig. 1 Areas of the literature review

\section{Literature review}

The research presented in this paper addresses the combination of three important research fields: Virtual Communities, Mobile Commerce, and Business Models. Whereas "Virtual Communities" have been discussed in the literature over many years, publications on "Mobile Commerce" indicate that one is still tackling an area full of forecasts, assumptions and sometimes speculations [27, 28, 37, 67]. Figures of the market of mobile devices are very promising [18]. The mobile phone is generally accepted as a personal device which most users would not like to miss. Telecommunication companies are looking for new, innovative business models for paid content and services for mobile devices. Figure 1 gives an overview of the research areas discussed in the following sections.

\subsection{Virtual communities}

Despite of the fact that there is a vast amount of literature on virtual communities (VC), there is still no consensus among researchers regarding the appropriate definition of the term "Virtual Community" [23, 47] although there have been propositions for classification schemes $[5,55,35,36]$. Neither has one of the many classification schemes really been accepted and adopted by the scientific community. In the context of this paper, it is important to notice that there are two fundamentally different kinds of communities which have been discussed controversially in VC literature: socially oriented communities and business communities. Hagel and Armstrong were the most prominent authors to discuss the value of business communities. There is an existing body of literature on potential benefits of virtual communities for business purposes $[5,6,11,20,24,26,52,56,72]$. As we will discuss later, mobile commerce resembles electronic commerce in some aspects.

In this paper, a mobile community is defined as an aggregation of individuals who interact around a shared interest (in our case spending their leisure time together), and where the setting up of the interaction is supported by mobile technology. 
This definition is in analogy with the one proposed by other authors. Rheingold [50] [e.g. $31,34,47]$ first conceptualized virtual communities as social entities. Several years later, [20] came up with the innovative idea to propose virtual communities as business models. This claim was often rejected by other authors in the aftermath of the publication of their book "Net Gain". In a study on Virtual Communities, [24] showed that more people use the Internet to participate in virtual communities than to make purchase transactions. The growth in membership and usage of virtual communities is still expected to continue [8].

People in virtual communities engaging in consumption-related activities can be an important source of marketing data [32]. There is a growing body of literature that addresses a consumer's willingness to exchange personal information with a marketer [38, 44, 54, 61]. [39] even offer anecdotal evidence of how companies have used virtual communities to support new product development efforts (see also [40, 45]. Some researchers have suggested that virtual communities are an opportunity to build deeper and more loyal relationships with consumers [10, 20].

We believe that the combination between social and economic goals might work well in a setting were the social ties between the members are strong and the economic goals are supplementary to the social relationships. Anecdotal evidence for this assumption can be found looking at existing platforms where members are personally affected by the topic of interest such as on the COSMOS platform for cancer patients [34] or the vast amount of forums for parental topics. This is the case for the support tool which we are presenting in this paper.

As [71] put it, virtual communities can be categorized based on the degree of virtuality which they constitute. According to Virnoche and Marx, the mobile community described in this paper would qualify as a virtual community. The wellness centre and its members represent a physical community. The sub-communities which are formed by segmenting the members' base into sub-communities (buddy lists) are virtual communities supported by mobile devices. This community structure is only formed in virtual space but constitutes itself in the physical realm. The borders of the sub-communities are permeable since at any given event, new members can be added or members who have been passive for a long period of time are likely to be removed. The WELL, one of the first and most well-known examples of a virtual community also had its roots in the physical world: the people of the neighbourhood in Silicon Valley [50]. In analogy to the WELL, our mobile communities could be called "virtual extensions" of their "real-world" counterparts.

The typology proposed by [35] is the one that best serves the purpose of this paper. Markus suggests three main types of virtual communities based on their orientation: Social, Professional and Commercial. The community that we are dealing with in this paper is a hybrid one that combines social and commercial aspects (c.f. Figure 1). Comparable to eBay, it falls into the class of $\mathrm{C} 2 \mathrm{C}$ communities, but clearly with the option for the platform provider to interact or even to intervene.

For our discussion of mobile communities we thus prefer to talk about hybrid communities (Figure 2). The community environment is composed of a Web-based part (the platform and member profiles) which can be managed using a Web browser. The mobile part of the community is focussed on communication via a mobile device. The active community is the sum of all currently active buddy lists (=people seeking to coordinate events and activities with other community members).

In terms of the platform (technical dimension) the mobile aspect of our community is asynchronous. Members broadcast their messages to the buddy list and people react whenever it is convenient for them. The consequences from the mobile interaction, the meeting at the club on the other hand, is purely synchronous. 
Fig. 2 Hybrid community addressed in this paper

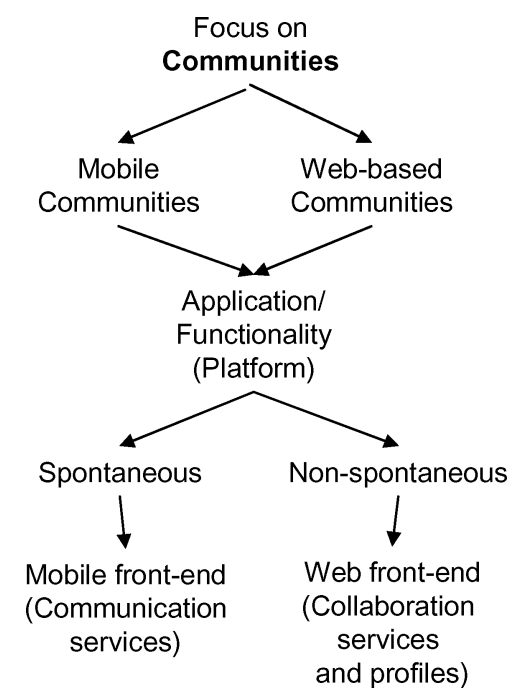

Focus on

The characterising attributes of VCs which are most often mentioned in literature are (1) place, (2) purpose, (3) platform, (4) population, and (5) profit model. Community platform operators will be well advised to find the right mix of attributes if they want to generate profits for their members.

An advantage for mobile communities described in this paper is the fact that they do neither need any external moderation nor a superimposed incentive structure. The motivation for becoming a member of the community comes with the desire to be part of a group of people engaged in leisure activities. The mobile community is highly "self-motivated" and moderated by each member autonomously.

The business model is an important aspect for the sustainability of a community platform. The operation of the platform is only feasible if the costs are fully covered on a long term basis [34]. Krishnamurthy [33] identified three different kinds of business models for the operation of a virtual community: community enablers, trading/sharing communities and communities as a Web site feature of corporations. In our case we are talking about the classical type of a community enabler. As will be discussed in more detail in the following chapters, members do not pay for the service. The platform will be sponsored by the recipients of the revenues that arise once the members have engaged in leisure time activities (sports, restaurant services).

There has been an intense discussion about the potentials of virtual communities in the last years. In most cases we have noticed that there is no way of forcing members into forming a community and gaining money with the operation of the platform. Anecdotal evidence has showed us that community members need to perceive a real value in the participation in a community. The following chapters will deal with the specific potentials of mobile devices for the support of communities and the business models that make community environments profitable for all participating parties on a long term basis.

\subsection{Mobile commerce}

In our paper, we follow the definition synthesised by Cronin from various sources about the nature of mobile commerce. 


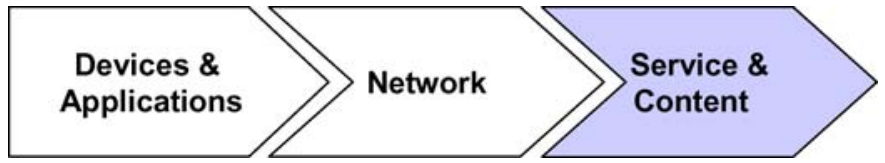

Fig. 3 The "traditional" value chain of mobile commerce

Mobile commerce refers to all data-driven business transactions and exchanges of value by users of mobile devices via wireless telecommunication networks [12].

In her paper, Cronin points out that some authors use an oversimplification of the term "mobile commerce" by stating that it is just "a wireless form of electronic commerce." There are some major differences which we became especially aware of when designing our mobile community prototype. Mobile commerce applications can be easily personalized to match individual situations. Koch et al. [31] call this mechanism "matchmaking". In contrast to electronic commerce where customers need a personal computer, a mobile device can easily be carried around and gives its user the potential of being always available to transmit urgent information or support transactions. This means that one can do business everywhere and at any time. There are limitations compared to e-commerce which have been discussed broadly [14], e.g. display size or the limited amount of data which can be sent using a mobile device. This is not a problem in our case as we only need to transmit small pieces of information such as event triggers or short messages.

The intriguing question in today's mobile commerce is the question of "who is making the profit in the emerging value chain?" Classically, there are at least three major interest groups involved:

1. Providers of mobile devices (e.g. mobile telephones)

2. Network operators (telecom companies)

3. Value-added service providers (content providers)

These interest groups correspond with the owners of the three steps of the mobile value chain as described by [69] or in an extended, generalised form with many more players involved by [73].

Our research is positioned at the end of the value chain in the area of "service \& content"called "secondary services" by [69]. In our business scenario, we assume that community members are equipped with a Java-capable mobile telephone (e.g. Siemens S55, SonyEricsson P900 etc.) and have a contract with one of the main network operators (providers of so-called "primary services") offering GPRS. Our analysis does not include the business models of the primary service providers. In our discussion we assume that they are "already in place."

Previous research in the area of "secondary activities" has shown that end consumers are usually not willing to pay a premium on services and content-unless they reap a direct benefit from it. In our "business model" the consumer receives the service for free. The other involved parties - the operator of the wellness centre and the tenant of the restaurant-are the ones who pay for the service, since it increases their potential revenues.

\subsection{Business models}

Following [16], a healthy business model for a community depends on the "just" distribution of perceived value and cost. As long as the players have the feeling that what they receive 且 Springer 
is worth its money, they are likely to accept the service and contribute to its cost by paying either member fees or certain amounts in per use (pay-per-use).

The term "business model" has evolved into a buzz word over time. Many authors point out that there is no clear definition of the term and that it has been defined varyingly in literature [3, 46, 48, 64, 65, 68]. Rentmeister and Klein [49] propose that a well-defined business model can be used as a reference for the analysis of performance and revenues with a value chain or a value web [59]. Within new network structures (such as value webs) the business model becomes the main unit of analysis for the allocation of resources and the distribution of profits among the different players $[19,65,66,68]$. Complementary partners have a share in the generation of the product or service as well as a share in the stream of revenues. Osterwalder [43] drives research on business models even further by proposing an ontology for different business models. Some authors even attach a time aspect to the term business model. They speak about a "life cycle model" with different phases in the evolution of a particular business [13, 25].

Following these ideas, we will take a particular look at the value constellation for mobile services and their supporting Web platforms. We will choose the often used definition of the term business model by [64] in our paper and use its components for the discussion of mobile communities as defined in the previous chapters.

In the process of finding a suitable definition for the term "business model" in the context of e-business we looked at current literature and found many different approaches [e.g. 4, 21, 43, 66, 68]. In the nineties, several methods like ARIS [53] or PROMET [42] were developed with the intention to help companies to model their processes and to develop and implement business information systems. Authors observe that the increased use of the term is closely related to the emergence and diffusion of online business [19, 58]. Internet start-ups which were highly reliant on financial investors in the so-called "New Economy" used the term to differentiate themselves from other businesses and to explain their superior competitive position.

The term "business model" appeared in computer science journals in the 1970s. After 1995 it became popular in business and computer magazines such as Business Week or Wired. In business as well as in academia the term is not consistently used, rarely explicitly defined, and often confused with "strategy". Some authors use the terms "strategy" and "business model" interchangeably.

Taken literally, a Business Model is a model of an existing business or a planed future business - a simplification of the complex reality. It helps us understand the fundamental components of an existing or future business activity. As a result of his extensive work on business models, [64] came up with a definition of business models which comprises four main components: (1) Value Proposition, (2) Product or Service, (3) Value Architecture and (4) Revenue Model.

\section{Value Proposition}

The description of the value a customer or a partner (e.g. a supplier) receives from the business. The corresponding question is:

What value does the business create for its stakeholders?

\section{Product or Service}

A business model contains a description of the product or services with which the company is present on the market. The question is:

What does the company sell?

\section{Value Architecture}

The description of the architecture of value creation. The value architecture describes the value chain, the economic agents (players) that participate in the value creation and their 
respective roles. The value architecture answers the question:

What is the value and how is it being created?

\section{Revenue Model}

After the What and How the basis and the sources of income have to be defined. Value and sustainability of the business is being determined by its revenue model. The revenue model answers the question:

Where and how do profits accrue?

In a value web, where multiple players interact and jointly offer the product or service to the customer, the question of the sharing of cost and benefit (revenue) is of special interest. Besides the actual contribution of products there are often other factors (such as governance structures, initial market situation, position in the supply chain, possession of customer profiles) that determine the allocation of cost and revenues. In the following chapter we will apply these definitions on the special case of mobile communities.

\section{Discussion: A business model for the mobile community}

Together with a business partner, we investigated a business case for a mobile servicean online reservation system with a mobile community extension. Robinson, a company specializing in club holidays for German vacationers, started a new business sub-unit in 2002 bringing their highly successful concept of "club vacation" into the cities. The new business concept is called "Robinson Well-fit in Town" [51]. When approached by the authors of this paper, Robinson Managers showed an interest in an innovative mobile application for their Well-fit centres. So far, they have been offering an online reservation system for the advanced booking of squash courts and some wellness services for their members. We suggested extending this service using a mobile community support platform.

As outlined before, we started the research project by analysing the literature on virtual communities with a focus on their reasons for success or failure. As described in the following paragraph, we especially started to look at business models and the motivational factors which provoked the members to use the service. After a couple of structured interviews with responsible people at Robinson, we had a fair idea of how such a system could look like. Endowed with the assessment of the potentials by the future operators we came up with the concept for a prototype which was built on top of their existing online reservation system. The new system was named MCOR (Mobile Community-enabled Online Reservation System). The prototype was developed and tested and is ready to be implemented. The first pilot implementation is planned to become part of the project "Maschsee Hannover" which is likely to start in the last quarter of 2004.

An investigation of the Internet showed that there are already a couple of similar but less complex services in operation. One example is golf.ch, a WAP-portal where users can find the nearest golf course in their present region [17].

All parties within the value chain, the users themselves, the service providers, the wellness centre operator and finally any restaurant leaseholder will face a win situation with such a system. This does not imply that each player will be willing to assume the same amount of investment and transaction cost. We will need to consider business models that are much more subtle.

For the user the mobile service provides convenience in arranging their leisure activity and it guarantees availability of the necessary resources. Provided the service will include an automatic (mobile) payment mechanism as well as a reminder service in addition to the 
standard notification procedure, the perceived convenience might even be extended. We will have to deal with the "price of convenience" issue as generally discussed by [41].

The operator of the wellness centre is getting a variety of advantages following the successful launch of MCOR. First, the predictability of resource planning will be improved and the financial liquidity could be enhanced if the effective charging takes place at the time of booking. Secondly, MCOR will help to increase customer loyalty, or more precisely it will create customer retention by locking the customers to the system as they get used to the increase in convenience. Changing wellness centres would then become awkward (resulting in increased switching cost) as all buddy lists would have to be set up from scratch, not to mention the possible loss of community adherence. This stream of arguments follows the well-known theoretical considerations as formulated by [60]. As a third argument, we expect that an increase in automatic booking lowers the operational cost (labour cost) since booking processes today are done mostly by employees via telephone.

The restaurant leaseholder might primarily be interested in issuing special offers to groups who get together using the MCOR service. Since they are characterised by advance booking and are members of a high income class they are prone to lavish consumption. They are also a target for cross- or up-selling activities (bring your friends, happy hour dining, special of the week etc.). As a consequence this should lead to an increase in revenues.

Finally, one might expect that the mobile carrier (the telecom company) has an interest in launching such a service, as it will generate additional air-time (including message or packet volume). This argument, on the other hand, may be controversial since the flip side of using MCOR are extensive telephone conversations for getting all the details arranged, which could prove to be even more profitable.

\subsection{Value proposition}

The customer is represented by the group of people subscribed to the platform (represented in the form of an aggregation of all buddy lists). They are either seeking leisure partners or answering to such requests. The main value consists of the possibility of semi-automatic and nearly spontaneous arrangements of leisure events characterized by a high degree of automation and resulting into reduced cost (made possible by the reduction of coordination time). A similar service was developed by the Technical University Muenchen. Its called COSMOS and it offers a coordination platform for students which makes use of a Webbased platform (containing the user profiles) and mobile devices for the coordination of spontaneous arrangements [31]

The time saved for arranging the event using the mobile service can be significant and it might even help that the event actually takes place. This might be difficult to express in terms of money, as it merely corresponds to otherwise unattained pleasure. This argument can be extended to those customers representing the group of invited buddies, as they would neither have gained access to the leisure activity otherwise. For all the participating parties offering services (see left column in Figure 4) to the customers, the value generation is made up by the additional revenue this group of customers will create at any single event that actually takes place. On a macro-economic level one could even argue that the facilitation of leisure events has a beneficial side-effect on public health.

\subsection{Product or service}

The description of the products and services can be derived from the value proposition. Services for awareness and coordination for upcoming leisure activities as well as the chance 
to spontaneously link customers in this process constitutes the main "product." The operator of the Web-based platform may also consider offering an indirect access to a targeted member group on the platform for other business partners (intermediary service).

\subsection{Value architecture: players and processes}

Looking at the players and processes (Figure 4) it can be seen that we are not dealing with a traditional value chain but with an innovative value web [59, 58]. Telecommunication companies do not play an active role in this value architecture. Their role is limited to a mere provision of the infrastructure. Without their carrier services the value adding services (the products) do not work but they do not provide any particular context-sensitive input to the scenario. This reflects the misconceptions in the discussion of UMTS and its likelihood for "failure" that has been discussed in recent press reports. UMTS per se cannot fail-it is a mere infrastructure; but telecommunication companies can fail in setting up services that are calling for UMTS. And usually the players offering the services are not under the influence of telecommunication companies. This is the reason why telcos are increasingly becoming information providers themselves or buying their way into information providing companies, so called full service providers (e.g. Deutsche Telekom AG).

Figure 4 shows the different players and processes in our community scenario. On the one hand there are different kinds of information or service providers. It can be assumed that the community platform will be established and promoted by the party that is most interested in building up the service. This will usually be the one that is likely to reap most benefits. Other interested parties on the sell-side are restaurants, sport shops, or specialized content providers.

In our case the leisure service provider (e.g. the operator of a fitness centre) will play the role of the main operator of the platform. There are different aspects that qualify one player above all others to play the decisive role in setting up the platform. Apart from financial aspects, the leisure service provider is the one that has already established relationships with the potential community members. The community platform will address his current customers, namely the people which are already enrolled members. Usually this means that he has an (electronic) database with information about his customers (member profiles).

In Figure 4 we distinguish between three different processes:

1. Information flow

2. Money flow

3. Activity triggers

Information flow: The sell-side players are the main information providers in respect to their services (free time of courts, rentals, trainers, restaurant specials, products, etc.). Their information flow is unidirectional. The customers on the other hand are also information providers. They are in charge of providing the community platform with their preferences (interests) and buddy lists. Provided they opted-in, they receive personalized information from the sell-side players. Community members thus benefit from a bilateral information flow: they teach the system and the system acts accordingly.

Money flow: On the customer side payments occur only for membership and connectivity. The air time used (for mobile services) and the Internet connection (for Web-based services) are payable to the telecommunication companies. The use of the community platform should be charged in the form of a subscription fee (flat rate) that is connected to the physical membership (compare discussion on the revenue model in following section). 


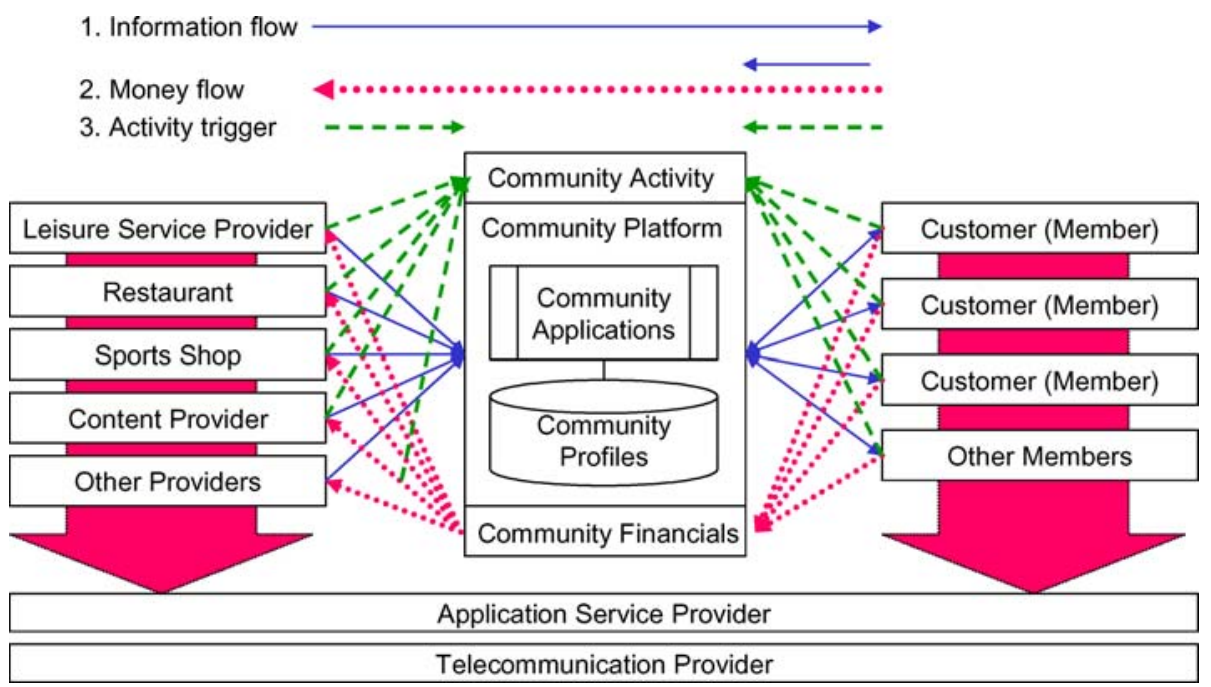

Fig. 4 Research framework: Players and processes

Activity (trigger): Processes are always triggered by one of the participating parties. In most of the cases this will be the customer searching for a leisure partner. On the sell-side this trigger can come in the form of information specials (such as events, lower prices, last minute offers) that are directed towards customers depending on preferences in the member profile. One major prerequisite is the prior consent of the customer in the form of an explicit desire to receive such information (opt-in). A special strength of the system is the use of interest profiles for targeted messages. In the event of a special squash tournament the system would send out SMS messages to members that play squash at a certain level and have activated the respective section in their interest profile.

\subsection{Revenue model}

The discussion of the revenue model is especially interesting in the described value architecture which is characterized by a multitude of different partners. The revenue model in this scenario will be based on a simple cost/benefit analysis. Each player faces the same question: What are my costs (fixed and variable) and what are the potential benefits? The community platform is a shared cost service where each sell-side player needs to pay for a part of the fixed costs of setting up and operating the platform. Additionally, there are variable costs depending of the number of activities that are triggered by the providers. Each time a piece of information (e.g. an SMS) is sent to a customer the resulting air time needs to be paid for.

There is evidence in the literature [58] that direct revenues from the community platform should only accrue in the form of subscription fees. This is comparable to the current practice of newspapers and magazines which offer online access to subscribers at a slightly higher fee than their regular paper products. This means that the leisure service provider will be the only player that can charge fees for the use of the platform. All other players will have to finance their participation by indirect revenues from increased sales, better customer service, higher degree of customer satisfaction, resulting customer retention, increased switching cost, etc.

Benefits, on the other hand, will be difficult to assess. There are some events that directly result into turnover (e.g. a last-minute court booking that would not have taken place with a 
lack of information or a party celebrated by a group of members specifically after a special offer has been sent out). Side benefits such as higher degree of customer satisfaction or even customer retention are hard to assess financially.

Since every player in the value web has an interest in the platform and directly or indirectly benefits from it the main provider could think of a revenue model in which each player pays fees according to the amount of turnover that he expects from the platform activities. This idea will be hard to realize since the turnover resulting from platform events cannot be assessed on a one-to-one basis (a calculation for event $\rightarrow$ result is not possible). It is thus recommendable that participating parties pay fees according to the expected level of benefit from the platform. It will be a matter of negotiation to find the optimal finance model.

The main operator of the platform which is in control of the user profiles is likely to bear the larger share of the cost as a future investment. He will be the one that profits over time when the platform will increase its value. The more detailed the member profiles become the more value can be attributed to the community platform. The platform operator who "owns" the platform and the underlying database will be the one that benefits most in the long run. It is likely that there are alternative business opportunities that will arise over time (e.g. targeted advertisements or banners on the community web sites), especially with respect to any crossor up-selling campaigns.

\subsection{Summary of the business model}

In their paper on Business Models for the Public WLAN Market [62] give an overview of the assumptions of the different market players. In analogy, we have prepared a summary of the components of our proposed business model and the respective roles and expectations of the players involved in the mobile community platform in Table 1.

\section{Developing a community support for well-fit centres}

Following up on our discussion of the potential business model, the following paragraphs describe the IT background in the Well-fit centres, the general requirements for the mobile application and the current MCOR prototype.

\subsection{Background: Leisure industry}

The leisure industry has seen an enormous growth over the last few years in most industrialized nations. For a literature overview we refer to [1]. Not only have the number of working hours decreased (in Germany typical working hours per week have been reduced from 40 to between 38 and 35.5) but also overall wellness and health awareness has impacted on and dispersed within all population groups [9]. Wellness activities have become a regular part of people's lives and are valued higher than conventional sporting exercise. Companies increasingly offer their staff free access to well-equipped in-house facilities or to third-party wellness centres (using a corporate contract). Such corporate incentives are generally welcomed (and now sometimes even expected) by employees. In general, most wellness activities are undertaken outside working hours and rarely alone. They are in fact now often perceived as community events organized around a nucleus of the wellness action.

After coming up with the idea of designing a prototype for a mobile application for reservations, we first had to analyse the current use of IT in our target sector. Most leisure centres use IT systems that are cash register-based enhanced by a customer data system. In 


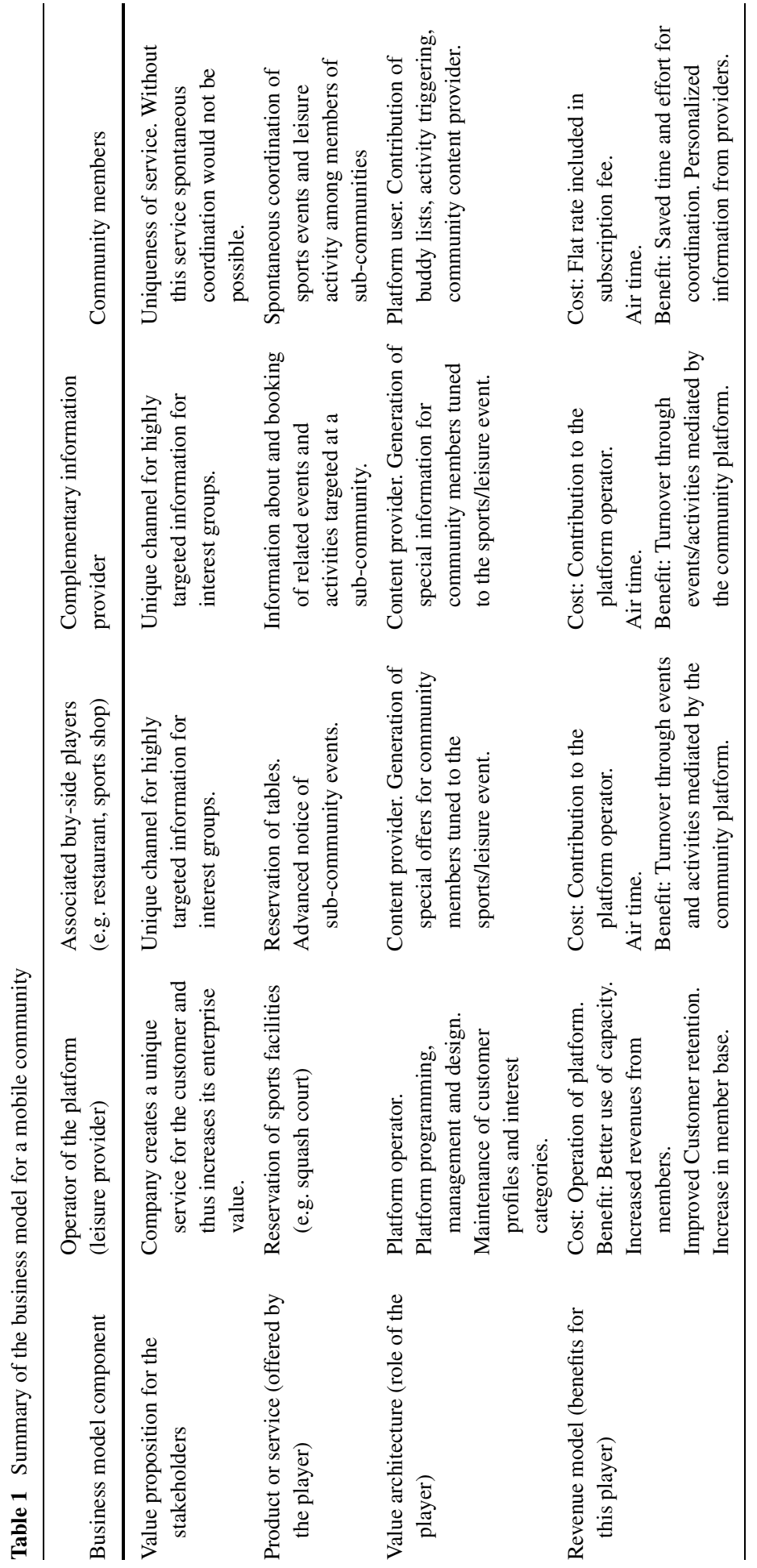


some cases they allow for reservation of resources (e.g. courts or coaches) and occasionally even for personal customer training plans. The users have access via dedicated systems either within the centre (kiosk-systems) or via the Web. Simple pricing models (e.g. flat rate subscription) can be enhanced by more sophisticated strategies such as last-minute discounts, pay-per-use and so on.

Existing IT-systems focus solely on planning and reservation of resources and do not support the social aspects of interaction between the customers. Many activities (e.g. tennis, concerts, and sports events) require the presence of others. Thus people often seem to direct their intrinsic motivation to social recreational activities. Empirical evidence in favour of social interaction as a motive for leisure time activity is strong [2]

Most systems include front-office and back-office components. These are often complemented by a database system that stores client data (accounting information, training plans, health-status parameters etc.). Back-office systems focus on daily routine procedures and data collection.

\section{The prototype: Java-based application for mobile telephones}

A system for the coordination of leisure time activity needs to meet several requirements, including:

- Convenient communication through user-friendly interfaces for the customers on all media channels. The systems requirement is to offer a community platform through synchronous and asynchronous communication media. Mobile devices must be strongly integrated in order to ensure that the system can be used ubiquitously.

- An instantaneous multidirectional information flow supporting awareness and confidence in the completion of the process of user matching and reservation

- Reliability, privacy, and trust as with most other services (further discussion of this aspect is beyond the scope of this paper).

The service elements used in the present context can be classified into three categories:

Push Services can only be effectively offered within areas of common interest (which are difficult to specify) or in cases of emergency. In any other case (e.g. advertisements or unwanted information) this approach to service-delivery tends to create a disturbance for the user.

Push Services "on demand" are less intrusive and more flexible. Via the Web the user may, for example, specify categories of interest. The service challenge is to offer adequate categories and to allow them to be combined flexibly into a "personal profile" while anticipating and offering appropriately targeted information. Problems arise whenever individual user requirements (the personal profile) cannot be defined within the categorisation scheme offered. To ease this problem the categories need to be very detailed, but there is an inevitable trade-off between providing a large variety of categories and keeping the system simple. Pull Services do not face this problem because the user chooses the desired services on an ad-hoc basis.

The scenario described in the introduction of this paper can be depicted as follows. The initiator (the community member) is already enrolled as a registered user of MCOR and has set up a buddy-list. Through a Web interface he makes a reservation for a squash court and a table in the club restaurant afterwards. He indicates that he wishes to contact a friend who is comparably good at squash as he is (such details are stored in the system's database). The reservation is then pre-processed. An invitation is issued to an appropriate friend, who must 
either accept or reject the invitation within a limited timeframe. In case of a rejection, the inviting party is being informed and may either manually restart the process or a second partner could be contacted automatically (depending on the setup in the preference profile of the user). Once the invitation has been accepted by a friend, both parties receive a feedback combined with additional information (time and location of the court, special prices for an extra period, or advertisement for the "special of the week"). They may even receive a voucher for food or drink as common in some cinemas in combination with the use of a customer value card. Kino Basel $[29,30]$. In the case that our user has set up one or more buddy-list(s), he may choose to inform all people from his list (the option of rearranging the order should be given). He has afterwards to decide whether he accepts either the first positive answer or follows any other selection strategy, leading perhaps to further (pair-wise) appointments or conflicts due to rejections.

In addition, the system could allow for additional cross- and up-selling campaigns. For example, based on the information in the customer interest profile (e.g. hiking or biking), information about upcoming outdoor events could be transferred to the user. This way, the time necessary for spreading activity-oriented information is minimised and a group can spontaneously plan such activities at short notice.

\subsection{The MCOR prototype}

It would be beyond the scope of this paper to present the full details of design and implementation of the prototype here. We consider the description of the general architecture of MCOR as most beneficial to our earlier discussion of mobile commerce and virtual communities.

At the bottom layer we connect to the leisure provider's operational system, accessing the DBMSs containing customer and transaction data. Thus MCOR will be an attached system, lowering the risk of missing compatibility in case of existing legacy IT-infrastructure.

The solution provider's part of the MCOR system can be hosted anywhere, allowing outsourcing (to an ISP) or any centrally managed service model. In principal, these two sites could be merged into a set of dedicated servers. Depending on the media channels offered for customer interaction, the Web servers have to support different communication interfaces. At present only SMS, J2ME and email communication has been realised.

\subsubsection{The web interface}

As mentioned above, we built the mobile enhancement of MCOR as an add-on to the existing CR-Online Reservation System. The latter is a Web-based solution for resource reservation which was launched as a separate product in 2002. It is possible to manage all services via this Web site, e.g. user preferences and security settings, or buddy-list membership. Using an Internet access, the MCOR-notification process could be started directly via any Web browser.

\subsubsection{The MCOR-system}

The steps which a user will typically perform are the following: He starts with a request for the booking of a resource, invites his buddies to accept this invitation and awaits the acknowledgment. Depending on the preferred channel either all buddies receive this specific invitation instantly or iteratively and can then confirm, deny or ignore it. The MCOR-system distributes the incoming answers, thus acting as a message hub. All parties involved may 
inquire the status of all pending invitations at any time. Furthermore, they have the option to invoke additional events which would turn the evening into a real community event.

\section{Outlook and further research}

The discussion presented in this paper opens a wide range of future research perspectives. The following list is neither meant to be coercive nor exhaustive.

First, we need to concentrate on user acceptance of the service in general and the improvement of the user interface design by conducting usability surveys. The study will include the business dimension by means of carefully monitoring the activity handled via the system right from the start of the operation of the service. Once the service has been launched, any customers cancelling the service or holding a subscription but not using it should be interviewed. Different ideas of how to get customers to subscribe to the systems have already been examined.

The next step in this research project will be the identification of the final business model for our prototype together with the implementation partner. We plan to perform a survey asking all players about their interest in the new service and their willingness to join a shared cost model. The question that will ultimately define the success of our implementation is the following: "Who will be willing to pay for the fixed and variable cost of the service and host the platform?" After a thorough literature review and interviews with our business partners we figure that this will not necessarily be the party that gains most profit from it.

Another challenging research item will focus on deploying the MCOR-approach to other domains. This would stimulate the need to develop a generic software platform. Questions related to this are: Which branches are suitable for mobile community support and how do they differ with respect to the underlying business conventions and operational aspects?

Finally, the MCOR-system could be technically enhanced by adding a voice portal interface, which would allow the users to interact with the system via natural speech. There are mature software platforms on the market, but the complicated part resides in the seamless media-integration and the semantic precision.

As soon as a sufficient number of other mobile services will be in place, we will extend our research methodology using cross-case analysis [15]. By aggregation of results from other studies on mobile communities (e.g. [22, 62]) we should be able to draw a more precise picture of the interdependencies of different mobile community approaches with respect to the theoretical concepts of communities in general. Conventional IT systems in the leisure industry are mainly focused on accounting and supporting the internal organisation of companies. The proposed mobile reservation system goes significantly further by adding support for the users' requirements. The main challenge on the social level is the combination of leisure activities with communication and simultaneous interaction with other people. On the technological level, the challenge is the integration of different communication and media channels.

\section{Conclusions}

The paper presents a description and an application of a general framework for business models for mobile services. Looking at a self-developed software application of a mobile service as an example, we discussed the question of a valid business model for such a service following [64] definition of business models. Although this paper has its limitations in that it only looks at one specific mobile service we think that the discussion will be valuable for other service providers, too. 
Mobile hybrid communities are a powerful approach to overcome difficulties in organising leisure activities. Especially the aspects of ubiquitous access to a community as well as to new services enabled through innovative mobile technologies seem very promising. In our opinion, telecommunication companies are the real winners in the described value web. The system can only be operated using their services and they have no fixed cost. Their infrastructure is ready in place and any additional activity increases their potential profits.

\section{References}

[1] Academy of Leisure Sciences (2004). Academy of leisure sciences. Available at http://www. academyofleisuresciences.org/alsbooks.htm.

[2] Ahola, P. (1980). Leisure needs and motives. Social Psychology of Leisure and Recreation, WCB.

[3] Alt, R., \& Zimmermann, H.-D. (2001). Introduction to special section-Business models. Electronic Markets, 11(1), 3-9.

[4] Amit, R., \& Zott, C. (2001). Value creation in E-business. Strategic Management Journal, 22, 493-520.

[5] Armstrong, A., \& Hagel III, J. (1995). Real profits from virtual communities. The Mckinsey Quarterly, $3,126-141$

[6] Barnatt, C. (1998). Virtual communities and financial services-on-line: Business potentials and strategic choice. International Journal of Bank Marketing, 16(4), 161-169.

[7] Bonoma, T.V. (1985). Case research in marketing: Opportunities, problems, and a process. Journal of Marketing Research, 12 (May), 199-208.

[8] Bressler, S.E., \& Grantham, C.E. (2000). Communities of commerce: Building internet business communities to accelerate growth, minimize risk, and increase customer loyalty. New York: McGraw-Hill.

[9] Brokmann, A. (1997). About the leisure attitude of the germans (original title: "Zum Freizeitverhalten der Deutschen"). Hamburg.

[10] Brown, S.L., Tilton, A., \& Woodside, D.M. (2002). The case for on-line communities. The McKinsey Quarterly No. 1.

[11] Bughin, J., \& Hagel III, J. (2000). The operational performance of virtual communities-towards a successful business model. Electronic Markets, 10(4), 237-243.

[12] Cronin, M.J. (2003). Mobile commerce-Internet encyclopedia. Boston: Carroll School of Managemen, Boston College.

[13] Damsgaard, J., Horsti, A., \& Nilsson, O. (2004). Sustainable evolution of business models: Cases from scandinavian internet portal market. Proceedings of the European Conference on Information Systems (ECIS 2004), June 14-16, Turku, Finland.

[14] Durlacher Research Ltd. (1999). Mobile commerce report. Available at http://www.durlacher.com/ research/res-reports.asp (06.02.2001).

[15] Eisenhardt, K.M. (1989). Building theories from case study research. Academy of Management Review, 14(4), 532-550.

[16] Ginsburg, M., \& Weisband, S. (2002). Social capital and volunteerism in virtual communities: The case of the internet chess club. Proceedings of the 35th HICSS Conference, Hawai.

[17] Golf C.H. (2004). Golf in Switzerland. Available at http://www.golf.ch/en/index.htm (31.01.2004).

[18] GSM World (2004). GSM Statistics. Available at http://www.gsmworld.com/news/statistics/index.shtml (31.01.2004)

[19] Haertsch, P. (2000). Competetive strategies for electronic commerce: A critical analysis of classical strategy concepts (original title: "Wettbewerbsstrategien für Electronic Commerce: Eine kritische Überprüfung klassischer Strategiekonzepte)", Köln, Josef Eul Verlag GmbH.

[20] Hagel, H., \& Armstrong, A. (1997). Net gain: Expanding markets through virtual communities. Boston. Harvard Business School Press.

[21] Hamel, G. (2000). Leading the revolution. Boston, MA: Harvard Business School Press.

[22] Hampe, J.F., \& Schwabe, G. (2003). Enhancing mobile commerce: Instant music purchasing over the air. In K.V. Anderson, et al. (Eds.), Seeking success in E-business (pp. 107-130). Dordrecht 2003: Kluwer Academic Pubishers.

[23] Hillery, G.A. (1955). Definitions of community: Areas of agreement. Rural Sociology, 20(2), 11-123.

[24] Horrigan, J.B. (2001). Online communities: Networks that nurture long-distance relationships and local ties. Pew Internet and American Life Project, http://www.pewinternet.org/reports/toc.asp?Report=47.

[25] Horsti, A., Tolonen, J., \& Brännback, M. (2004). Electronic business models: Five cases from five industries. Proceedings of the European Conference on Information Systems (ECIS 2004), June 14-16, Turku, Finland. 
[26] Jones, Q., \& Rafaeli, S. (2000). Time to split, virtually: 'Discourse architecture' and 'community building' create vibrant virtual publics. Electronic Markets, 10(4), 214-223.

[27] Kalakota, R., \& Robinson, M. (2001). M-business-The race to mobility. New York: McGraw Hill Trade. 2001.

[28] Keen, P.G.W., \& Mackintosh, R. (2001). The freedom economy-Gaining the mcommerce edge in the era of the wireless internet. New York: McGraw-Hill, 2001.

[29] Kino B. (2004). Online booking kino basel. Available at http://www.kinobasel.ch (31.01.2004).

[30] Kitag (2004). Online booking KITAG. Available at http://www.kitag.com (31.01.2004).

[31] Koch, M., Groh, G., \& Hillebrand, C. (2002). Mobile communities-Extending online communities into the real world. Proceedings of the Eighth Americas Conference on Information Systems (AMCIS 2002), Aug. 5-8, New York.

[32] Kozinets, R.V. (2002). The field behind the screen: Using netnography for marketing research in Online Communities. Journal of Marketing Research, 39(1), 61-72.

[33] Krishnamurthy, S. (2003). E-Commerce management: Text and cases. Australia: South-Western, a division of Thompson Learning.

[34] Leimeister, J.M., Daum, M., \& Krcmar, H. (2003). Towards M-communities: The case of cosmos healthcare. Proceedings of the 36th HICSS Conference, Hawaii.

[35] Markus, U. (2002). Characterizing the virtual community. SAP Design Guild (5th ed.), http://www. sapdesignguild.org/editions/edition5/print_communities.html (01.09.2004).

[36] Mathwick, C. (2002). Understanding the online consumer: A typology of online relational norms and behavior. Journal of Interactive Marketing, 16(1), 40-55.

[37] MeT (2001). The met initiative-enabling mobile E-commerce. MeT Overview White Paper, Version 2.0, http://www.mobiletransaction.org/pdf/White\%20Paper_2.0.pdf. (29.01.2001).

[38] Milne, G.R. (1997). Consumer participation in mailing lists: A field experiment. Journal of Public Policy and Marketing, 16 (Fall), 298-309.

[39] Moon, J.Y., \& Sproull, L. (2001). Turning love into money: How some firms may profit from voluntary electronic customer communities.

[40] Nambisan, S. (2002). Designing virtual customer environments for new product development: Toward a theory. Academy of Management Review, 27(3), 392-413.

[41] Ng-Kruelle, G. et al. (2002). The price of convenience: Privacy and mobile commerce. Quarterly Journal of Electronic Commerce, 3, 273-285.

[42] Österle, H. (1994). Business engineering: Process and system development (original title: Business engineering: Prozess- und Systementwicklung). Berlin: Springer, 1994.

[43] Osterwalder, A. (2004). The business model ontology: A proposition in a design science approach. Ph.D. Thesis, Université de Lausanne 2004.

[44] Phelps, J., Nowak, G., \& Ferrell, E. (2000). Privacy concerns and consumer willingness to provide personal information. Journal of Public Policy \& Marketing, 19(1), 27-41.

[45] Piller, F., Koch, M., Möslein, K., \& Schubert, P. (2003). Managing High Variety: How to Overcome the Mass Confusion Phenomenon of Customer Co-Design. Proceedings of the 3rd Annual Conference on Managing through variety: The European style? European Academy of Management, April 3-5, SDA Bocconi, Milan, Italy.

[46] Porter, M. (2001). Strategy and the internet. Harvard Business Review, Vol. März, pp. 63-78.

[47] Preece, J. (2000). Online Communities-Designing Usability, Supporting Sociability, Chichester et al., Wiley.

[48] Rentmeister, J., \& Klein, S. (2001). Business models in the new economy (original title: "Geschäftsmodelle in der New Economy"). WISU das Wirtschaftsstudium, 30(3), 354-361.

[49] Rentmeister, J., \& Klein, S. (2003). Business models-A fashion term scrutinized (original title: "Geschäftsmodelle_ein Modebegriff in der Waagschale"). ZfB-Zeitschrift für Betriebswirtschaft, Ergänzungsheft (vol. 1, Ergänzungsheft), (pp. 17-30).

[50] Rheingold, H. (1993). The virtual community: Homesteading on the electronic frontier. Addison-Wesley Publishing Company.

[51] Robinson (2004). Robinson Well-fit. Available at http://www.robinson-wellfit.de/ (31.01.2004).

[52] Rothaermel, F.T., \& Sugiyama, S. (2001). Virtual internet communities and commercial success: Individual and community-level theory grounded in the atypical case of TimeZone.com. Journal of Management, 27, 297-312.

[53] Scheer, A.-W. (1992). Architectures of Integrated Information Systems-Foundations of Business Modelling (original title: "Architektur integrierter Informationssysteme-Grundlagen der Unternehmensmodellierung" 2nd ed.) Springer: Berlin.

[54] Schoenbachler, D.D., \& Gordon, G. L. (2002). Trust and customer willingness to provide information in database driven relationship marketing. Journal of Interactive Marketing, 16(3), 2-16. 
[55] Schubert, P. (1999). Virtual communities of transaction in electronic commerce: Management, marketing and social environment (original title: "Virtuelle Transaktionsgemeinschaften im Electronic Commerce: Management, Marketing und Soziale Umwelt"). Lohmar-Köln, Josef Eul Verlag.

[56] Schubert, P., \& Ginsburg, M. (2000). Virtual communities of transaction: The role of personalization in electronic commerce. Electronic Markets Journal, 10(1), 45-55.

[57] Schubert, P., \& Leimstoll, U. (2003). Paid content in the internet: A study about experiences and trends (original title: "Paid Content im Internet: Eine Studie über Erfahrungen und Trends"), Working Report EBusiness Basel, University of Applied Sciences Basel (FHBB), Institute for Business Economics (IAB), No. 12.

[58] Schubert, P., Selz, D., \& Haertsch, P. (2002). Digital success: Case studies about stra-tegic E-business concepts (original title: "Digital erfolgreich: Fallstudien zu strategischen E-Business-Konzepten") (2nd ed.). Berlin, Heidelberg: Springer.

[59] Selz, D. (1999). Value webs: Emerging forms of fluid and flexible organizations: Thinking, organizing, communicating, and delivering value on the internet. Dissertation, St. Gallen, Institute for Information Management, University of St. Gallen.

[60] Shapiro, C., \& Varian, H. (1999). Information rules. Harvard Business School Press.

[61] Sheehan, K.B., \& Hoy, M.G. (2000). Dimensions of privacy concern among online consumers. Journal of Public Policy \& Marketing, 19(1), 62-73.

[62] Shubar, A., \& Lechner, U. (2003). Business models for the public WLAN market. Proceedings of the Konferenz Wirtschaftsinformatik (WI 2003), Sept. 17-19, Dresden.

[63] Shubar, A., \& Lechner, U. (2004). The public WLAN market and its business models-An empirical study. Proceedings of the 17th International Bled Electronic Commerce Conference, June 21-23, Bled, Slovenia.

[64] Stähler, P. (2001). Business models in the digital economy (original title: "Geschäftsmodelle in der digitalen Ökonomie"), Lohmar-Köln, Josef Eul Verlag.

[65] Tapscott, D. (1996). Digital economy_Promise and peril in the age of networked intelligence. New York: McGraw-Hill.

[66] Tapscott, D., Ticoll, D., \& Lowy, A. (2000). Digital capital: Harnessing the power of business webs. Boston, MA: Harvard Business School Press.

[67] TIMElabs Research Center (2000). Winning in mobile emarkets. Eschborn, Diebold Deutschland GmbH.

[68] Timmers, P. (1998). Business models for electronic markets. Electronic Markets, 8(2), 3-8.

[69] Turowski, K., \& Pousttchi, K. (2004). Mobile commerce: Basics and techniques (original title: "Mobile Commerce: Grundlagen und Techniken"). Berlin: Springer.

[70] Vaishnavi, V., \& Kuechler, B. (2004). Design research in information systems. IS WorldNet. http://www. isworld.org/Researchdesign/drisISworld.htm (21.11.2004).

[71] Virnoche, M.E., \& Marx, G.T. (1997). Only connect-E. M. Forster in an age of electronic communication: Computer-mediated association and community networks. Sociological Inquiry, 67 (1), 85-100.

[72] Williams, R.L., \& Cothrel, J. (2000). Four smart ways to run online communities. Sloan Management Review, 41(4), 81-91.

[73] Zerdick, A., Picot, A., Schrape, K., Artope, A., Goldhammer, K., Lange, U.T., Vierkant, E., LopezEscobar, E., Silverstone, R., Artopé, A., \& López-Escobar, E. (1999). Internet economy: Strategies for the digital economy (original title: "Internet-Ökonomie: Strategien fuer die digitale Wirtschaft"), Springer.

Felix Hampe holds a chair for Corporate Communication Systems and is Director of the Institute for IS Research at the Faculty of Informatics of the University of Koblenz-Landau in Germany. He studied at the Free University of Berlin and worked later for the University of Bielefeld and the Philipps-University of Marburg prior to his appointment to Koblenz. In 2004/2005, he spent one year as a visiting professor at the University of South Australia, School of Computer and Information Systems. Beside his research interest in application aspects of communication systems, Professor Hampe started very early research in the area of mobile applications and especially mobile commerce. He was cofounder and board member of the Mobile Application Research Center (MARC), a German network for joint research on mobile business. Professor Hampe authored several international conference articles in the area and served for many international conferences. 